\title{
IMPROVED PARAMETERIZATION OF WATER CLOUD MODEL FOR HYBRID- POLARIZED BACKSCATTER SIMULATION USING INTERACTION FACTOR
}

\author{
S. Chauhan ${ }^{\mathrm{a}, *}$, H. S. Srivastava ${ }^{\mathrm{b}}$, P. Patel $^{\mathrm{c}}$ \\ ${ }^{a}$ Department of Natural Resources, Faculty of Geo-information Science and Earth Observation (ITC), University of Twente, \\ Enschede, Netherlands - s.chauhan@utwente.nl \\ ${ }^{b}$ Agriculture and Soils Department, Indian Institute of Remote Sensing (IIRS), Indian Space Research Organisation (ISRO), \\ Dehradun-248001, India - harishanker_srivastava@iirs.gov.in \\ c Space Applications Centre (SAC), ISRO, Ahmedabad-380015, Gujarat, India - parul@sac.isro.gov.in
}

Commission IV, WG IV/4

KEY WORDS: Water cloud model, Vegetation descriptors, Hybrid-polarized backscatter, Interaction factor, Leaf area index

\begin{abstract}
:
The prime aim of this study was to assess the potential of semi-empirical water cloud model (WCM) in simulating hybrid-polarized SAR backscatter signatures (RH and RV) retrieved from RISAT-1 data and integrate the results into a graphical user interface (GUI) to facilitate easy comprehension and interpretation. A predominant agricultural wheat growing area was selected in Mathura and Bharatpur districts located in the Indian states of Uttar Pradesh and Rajasthan respectively to carry out the study. The three-date datasets were acquired covering the crucial growth stages of the wheat crop. In synchrony, the fieldwork was organized to measure crop/soil parameters. The RH and RV backscattering coefficient images were extracted from the SAR data for all the three dates. The effect of four combinations of vegetation descriptors ( $V_{l}$ and $V_{2}$ ) viz., LAI-LAI, LAI-Plant water content (PWC), Leaf water area index (LWAI)-LWAI, and LAI-Interaction factor (IF) on the total RH and RV backscatter was analyzed. The results revealed that WCM calibrated with LAI and IF as the two vegetation descriptors simulated the total RH and RV backscatter values with highest $\mathrm{R}^{2}$ of 0.90 and 0.85 while the RMSE was lowest among the other tested models (1.18 and $1.25 \mathrm{~dB}$, respectively). The theoretical considerations and interpretations have been discussed and examined in the paper. The novelty of this work emanates from the fact that it is a first step towards the modeling of hybrid-polarized backscatter data using an accurately parameterized semi-empirical approach.
\end{abstract}

\section{INTRODUCTION}

With an increase in the number of earth observation satellites in the last few decades, use of satellite data has expanded in the context of regional and global monitoring of vegetation. The choice of satellite data to be used is particularly dependent upon the spatial and temporal scales at which the vegetation changes of interest can be studied effectively. During the growing season, monitoring of the crop condition becomes increasingly important so that the management factors (like fertilizer and irrigation applications) can be adjusted and enough information to predict the crop yields before harvest can be produced (Inoue, 2003; Doraiswamy et al., 2004).

Ever since the launch of microwave spaceborne sensors like Radarsat-2 and European Remote Sensing Satellites (ERS), several studies have tried to develop an understanding of the temporal backscatter variation of C-band SAR measurements from a wheat crop, with the view of extracting some valuable information (Ferrazzoli et al., 1997; Saich \& Borgeaud, 2000; Macelloni et al., 2001). The temporal backscatter response from the wheat fields, especially in X/C-band using vertical-vertical (VV), horizontal-horizontal (HH) and horizontal-vertical (HV) polarizations as well as at different incidence angles across the growing season has been well interpreted and documented in the literature (Cookmartin et al., 2000; Mattia et al., 2003; He et al., 2016). However, an understanding regarding the interaction of hybrid-polarized SAR signal with the crop cover is yet to be developed. The concept of compact polarimetry which emerged in the 1970s (Green, 1968) has been revived and is the nascent area of research (Souyris et al., 2005; Raney, 2007). The launch of ISRO's first indigenous microwave satellite RISAT-1 has made it feasible to explore the use hybrid-polarized data for crop studies.

Several modeling approaches like Water Cloud Model or WCM and Michigan Microwave Canopy Scattering or MIMICS model have been extensively tested in their original or refined form on several crops like wheat, maize, etc. using SAR data and have provided a broad understanding of the scattering mechanisms (Bouman, 1991; Bériaux et al. 2015). At the same time, process-based radiative transfer models have also been applied to carry out detailed investigations and simulate actual scenarios (Le Toan et al., 1997; Ballester-Berman et al., 2005). However, despite the higher accuracy, the inherent complexity in the inversion of complex multi-variable models and data intensive nature makes them highly infeasible (Inoue et al., 2014).

A robust model with adequate parameterization is thus required so that the complex interaction mechanisms can be properly understood (Ulaby et al., 1986). The assumptions made in water cloud model simplify the scattering processes by the averaging that takes place within a resolution cell, owing to the random distribution of orientation, size, and location of scatterers (Maity et al., 2004). Although easy to use, the modeling of backscatter using WCM remains challenging due to the absence of any standard implementation approach or any apriori method for evaluating its parameters (Bouman et al., 1999; Graham and Harris, 2003).

Several studies have reported different WCM parametrization techniques to model the total backscattering coefficients using 
the C-band data (Prevot et al., 1993; Dabrowska-Zielinska et al., 2007; Said et al., 2012). Dabrowska-Zielinska et al. (2007) investigated the applicability of three different canopy descriptors viz., leaf area index (LAI), leaf water area index (LWAI) and vegetation water mass (VWM) and found that at $23^{\circ}$ incidence angle, the attenuation of the soil signal by the canopy was strongest in case of VWM. In another experiment, Said et al. (2012) attempted to identify the prominent descriptor among, LAI, canopy height, and plant water content (PWC) using ERS-2 SAR data, so that the vegetation effects on soil moisture estimation could be eliminated. Although several refined versions of WCM have been published over the years, the vertical heterogeneity of a vegetation cover has never been described solely using a vegetation descriptor.

To this end, the potential of SAR signatures (RH and RV) retrieved from hybrid-polarized RISAT-1 data, has been assessed to model the backscatter using semi-empirical WCM approach. We also propose a potential combination of canopy descriptors that can account for the canopy inhomogeneity. Their impact on the total backscatter simulation has been evaluated and compared with other calibration methodologies, and the final results have been integrated into a graphical user interface (GUI).

\section{MATERIALS AND METHODS}

\subsection{Study area and data acquisition}

The study area lies in the state of Rajasthan and Uttar Pradesh (Figure 1), and is bounded between the latitude of $27^{\circ} 18^{\prime} 09^{\prime}$ ' $\mathrm{N}$ to $27^{\circ} 01^{\prime} 25^{\prime}$ ' $\mathrm{N}$ and longitude of $77^{\circ} 18^{\prime} 08^{\prime}$ ' $\mathrm{E}$ to $77^{\circ} 33^{\prime}$ 06 " E. The site is predominantly agricultural with wheat as a major crop.

Three-date RH and RV SLC images were acquired for the month of January, February and March 2015, covering the critical growth stages of the wheat crop. The specifications of the dataset are provided in Table 1. In parallel, a total of 140 observations were made for the crop parameters (like LAI, density, height, volume, etc.) across the season while 80 soil samples were collected from bare fields to record soil properties like volumetric moisture, roughness, soil texture, type, etc.

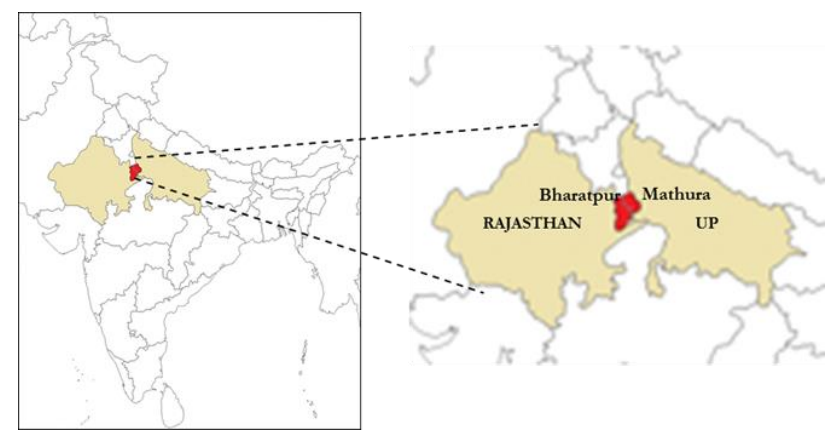

Figure 1. Location of the study area

The crop and soil samples were dried in an electric oven at 70 and $105^{\circ} \mathrm{C}$ respectively for 24 hours to obtain dry crop biomass, plant water content, and soil moisture (Figure $2 \mathrm{a}$ and $2 \mathrm{~b}$ ). The crop volume was estimated by immersing the plant samples in graduated measuring cylinders and measuring the amount of water displaced (Figure 2c).

\begin{tabular}{|l|l|}
\hline Swath & $25 \mathrm{~km}$ \\
\hline Imaging mode & $\begin{array}{l}\text { Fine Resolution STRIPMAP } \\
\text { (FRS-1) mode }\end{array}$ \\
\hline $\begin{array}{l}\text { Transmit } \\
\text { polarization (Tx) }\end{array}$ & Right Circular (R) \\
\hline $\begin{array}{l}\text { Receive polarization } \\
\text { (Rx) }\end{array}$ & Vertical (V), Horizontal (H) \\
\hline Azimuth Resolution & 3.33 meters \\
\hline Range Resolution & 2.34 meters \\
\hline Pixel Spacing & 1.8 meter \\
\hline Line Spacing & 2.37 meter \\
\hline Processing level & Single Look Complex (SLC) \\
\hline Incidence angle & $38.2^{\circ}$ \\
\hline Pass & Ascending \\
\hline
\end{tabular}

Table 1. Specifications of RISAT-1 datasets

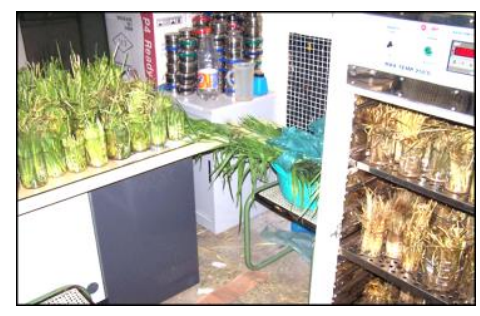

(a)

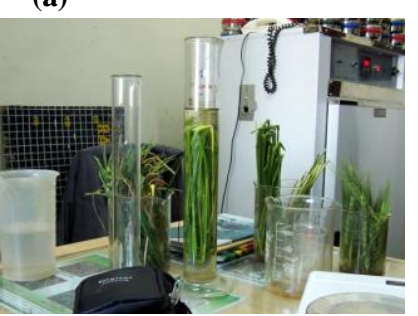

(c)

Figure 2. Measurement of (a) dry biomass, (b) soil moisture, and (c) crop volume

\subsection{Data pre-processing}

The images were radiometrically calibrated in PolSDP 1.0, which is an open source SAR data processing software. The dataset was then geo-referenced and filtered, so as to remove the speckle noise. The GPS field boundary vector layers were then used to generate the training windows for the sampled fields (in accordance with the statistical criteria proposed by Patel and Srivastava (2013) about the minimum number of pixels that need to be averaged in order to get a characteristic backscatter response) and the backscatter signatures from the images were extracted. The backscatter extracted from satellite data will be used as observed backscatter hereafter.

\subsection{Water Cloud Backscattering Model}

2.3.1 Model description: Attema and Ulaby (1978) conceptualized the WCM and its semi-empirical nature can be attributed to the fact that the model coefficients needs to be derived from the experimental data. The major conceptual assumptions made to formulate WCM include: 
- The dielectric horizontal cloud of identical water droplets comprising the vegetation canopy are distributed uniformly throughout the vegetation canopy,

- Only single scattering is accounted for, neglecting the multiple scattering taking place between the crop and the underlying soil surface, since at C-band, the double scattering mechanism has a negligible impact, especially in the case of thin canopy structures like wheat.

- The cloud density is assumed proportional to the water content per unit volume of the canopy.

- The backscatter contribution from soil is modeled from bare field locations for the sake of simplification.

The total backscatter ( $\sigma_{\text {total }}^{o}$ ) from a crop canopy at a given angle of incidence $\theta_{i}$, is given as an incoherent sum of the contribution of backscatter from a vegetation canopy $\left(\sigma_{\text {veg }}^{o}\right)$ and that from soil $\left(\sigma_{\text {soil }}^{o}\right)$, attenuated twice by the vegetation layer $\left(L^{2}\right)$ :

$$
\begin{gathered}
\sigma_{\text {total }}^{o}(d B)=\sigma_{\text {veg }}^{o}+L^{2} \cdot \sigma_{\text {soil }}^{o} \\
\text { with, } \sigma_{\text {veg }}^{o}(d B)=A \cdot V_{1} \cdot \cos \theta\left(1-L^{2}\right) \\
L^{2}=\exp \left(-2 B \cdot V_{2} \cdot \sec \theta\right) \\
\sigma_{\text {soil }}^{o}(d B)=C+D \cdot M_{v}
\end{gathered}
$$

where, $V_{1}$ and $V_{2}$ are the canopy descriptors; $\mathrm{A}$ and $\mathrm{B}$ are vegetation specific coefficients while $\mathrm{C}$ and $\mathrm{D}$ are the soil specific coefficients (Prevot et al., 1993), and $M_{v}$ is the volumetric soil moisture.

2.3.2 Model parametrization: Different sets of vegetation/canopy descriptors can be used to depict $V_{l}$ and $V_{2}$. These descriptors account for the complexity of the canopy structure. Since there is no theoretical basis to define the best set of descriptors and to predict the values of $\mathrm{A}$ and $\mathrm{B}$ coefficients, we tested four different combinations of descriptors (Table 2). We hypothesized that the combination that would best incorporate the water status, as well as the heterogeneity of its distribution within a confined volume, would stand out in accurately simulating the total backscatter.

\begin{tabular}{|c|l|l|l|}
\hline Sr. no & \multicolumn{1}{|c|}{$\mathbf{V}_{\mathbf{1}}$} & \multicolumn{1}{|c|}{$\mathbf{V}_{\mathbf{2}}$} & \multicolumn{1}{c|}{ References } \\
\hline 1. & LAI & LAI & Ulaby et al., 1984 \\
\hline 2. & LAI & PWC & Prevot et al., 1993 \\
\hline 3. & LWAI & LWAI & $\begin{array}{l}\text { Dabrowska-Zielinska et al., } \\
2007\end{array}$ \\
\hline 4. & LAI & IF & Tested in this study \\
\hline
\end{tabular}

Table 2. Combination of canopy descriptors tested for calibrating WCM

The interaction factor or IF (refer to Patel et al. (2006)) describes the distribution of plant moisture within a confined volume. The vegetation coefficients A and B were estimated by iterative optimization while soil coefficients $\mathrm{C}$ and $\mathrm{D}$ were determined by a regression analysis of $\mathrm{RH}, \mathrm{RV}$ backscattering coefficients, and soil moisture from bare fields. The backscatter simulated from WCM will be used as estimated backscatter hereafter. The results of WCM have been integrated into a GUI for easy comprehension. The GUI was designed in Python 2.7, a widely used OSI-approved open source licensed language, which is freely usable and distributable. Python has some GUI toolkits available.

\section{RESULTS AND DISCUSSION}

\subsection{WCM Parameterization I: Estimation of soil and vegetation coefficients}

To simulate RH and RV backscatter, the coefficients A, B, C, and $\mathrm{D}$ were estimated for all the four models (Table 3). As is evident from the table 3 , the soil coefficients are constant for each of the four models for a particular polarization since they are independent of canopy variables. The coefficients A and B were estimated using Levenberg-Marquardt optimization. The non-zero value of these coefficients suggests that the contribution from a vegetation canopy cannot be neglected.

\begin{tabular}{|c|c|c|c|c|c|}
\hline $\begin{array}{c}\text { Canopy } \\
\text { descriptors }\end{array}$ & \multicolumn{2}{|c|}{ Vegetation coefficients } & Soil coefficients \\
\hline V $_{\mathbf{1}}$ & $\mathbf{V}_{\mathbf{2}}$ & A & B & C & D \\
\hline \multicolumn{7}{|c|}{$\boldsymbol{C 3 8 . 9 ^ { \circ }} \boldsymbol{R H}$} \\
\hline LAI & LAI & 0.0378 & 0.0255 & -19.914 & 0.285 \\
\hline LAI & PWC & 0.0413 & 0.1547 & -19.914 & 0.285 \\
\hline LWAI & LWAI & 0.0602 & 0.1545 & -19.914 & 0.285 \\
\hline LAI & IF & 0.1702 & 0.3609 & -19.914 & 0.285 \\
\hline \multicolumn{7}{|c|}{$\boldsymbol{C ~ 3 8 . 9 ^ { \circ }} \boldsymbol{R} \boldsymbol{V}$} \\
\hline LAI & LAI & 0.0254 & 0.0147 & -23.168 & 0.278 \\
\hline LAI & PWC & 0.0386 & 0.1448 & -23.168 & 0.278 \\
\hline LWAI & LWAI & 0.0487 & 0.1475 & -23.168 & 0.278 \\
\hline LAI & IF & 0.1565 & 0.2586 & -23.168 & 0.278 \\
\hline
\end{tabular}

Table 3. Vegetation and soil coefficients for different models

\subsection{WCM Parameterization II: Canopy descriptors $V_{1}$ and $\mathbf{V}_{2}$}

3.2.1 Model I: V1 = LAI, V2 $=$ LAI: LAI or Leaf area index is one of the most widely used descriptors in water cloud model. Figure $3 \mathrm{a}$ and $3 \mathrm{~b}$ illustrates a validation line plot between observed and estimated RH and RV backscatter, respectively. A total of 20 points were used for validating the model performance. The model simulated RH and RV backscatter with a low $\mathrm{R}^{2}$ of 0.55 and 0.40 , respectively while the RMSE was

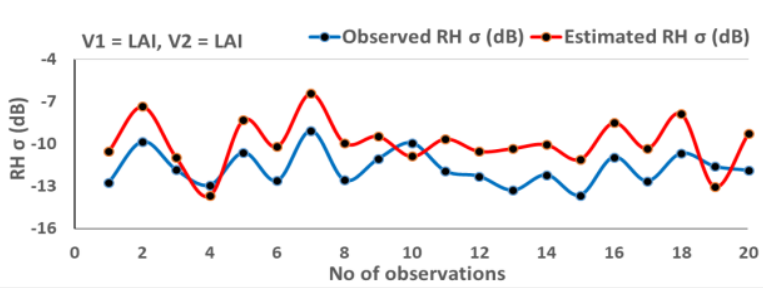

(a)

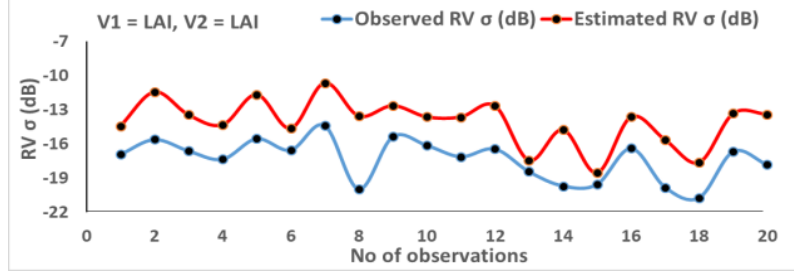

(b)

Figure 3. Observed v/s Estimated (a) RH and (b) RV backscatter for Model I 
quite high (Table 4). The possible explanation can be that LAI represents the vegetation canopy solely in terms of its leaf size and does not incorporate the dielectric properties.

3.2.2 Model II: V1 = LAI, V2 = PWC: LAI and Plant water content (PWC) were used as the vegetation descriptors in model II. A slight improvement was observed in $\mathrm{R}^{2}$ and RMSE (Table 4) and is quite evident in figure $4 \mathrm{a}$ and $4 \mathrm{~b}$. The model retrieved RH and RV backscatter with comparable accuracy. Although both density and dielectric traits of crop canopy were incorporated, the model performed moderately since the dielectric heterogeneity was not considered.

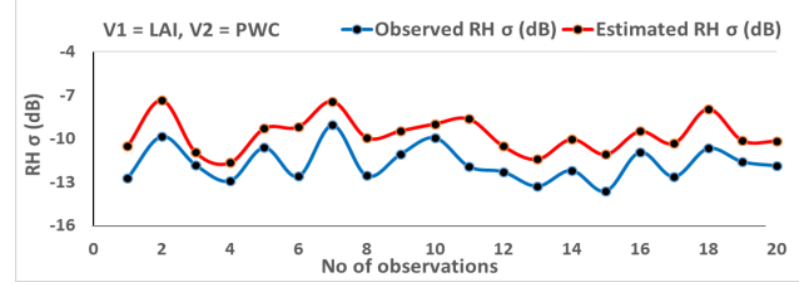

(a)

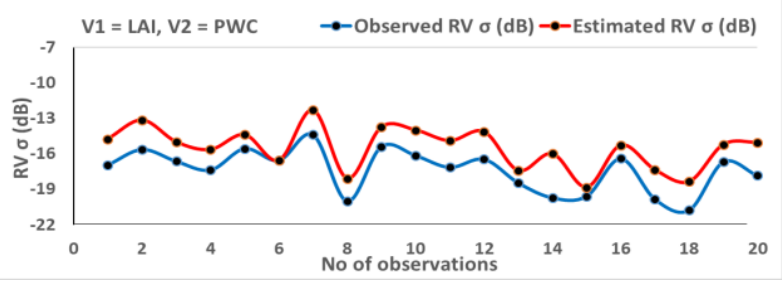

(b)

Figure 4. Observed v/s Estimated (a) RH and (b) RV backscatter for Model II

3.2.3 Model III: V1 $=$ LWAI, V2 $=$ LWAI: In this case, the performance marginally improved with the $\mathrm{R}^{2}$ of 0.72 for both RH and RV backscatter as can in seen in Table 4. There was a steep drop in RMSE of RV backscatter in comparison to model

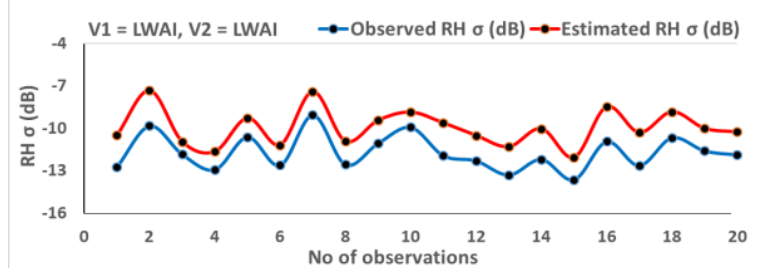

(a)

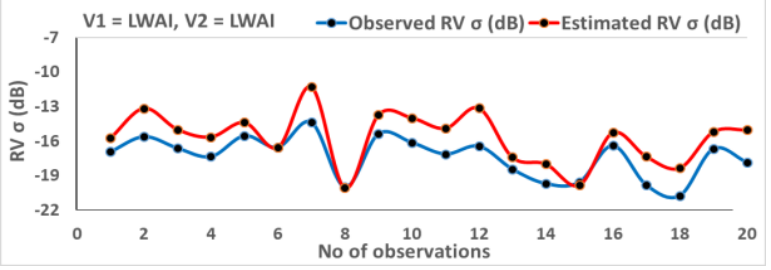

(b)

Figure 5. Observed v/s Estimated (a) RH and (b) RV backscatter for Model III
I (by $1.6 \mathrm{~dB}$ ) while for $\mathrm{RH}$, the decline was quite gradual (by $0.4 \mathrm{~dB}$ ). The validation plots have been illustrated in Figure 5a and $5 \mathrm{~b}$. Thus, we can infer that LWAI depicts the vegetation canopy in a better way than previously tested descriptors.

3.2.4 Model IV: V1 = LAI, V2 = IF: A significant improvement was witnessed when the combined effect of LAI and IF was considered. The model outperformed the other models with highest $R^{2}$ of 0.90 and 0.85 , respectively (Table 4). Except a few, the majority of points were in close agreement with the observed ones as can be seen in Figure $6 \mathrm{a}$ and $6 \mathrm{~b}$. The interaction factor is a composite of different plant parameters (plant volume, density, height and moisture content) which determines the distribution of moisture within a confined volume, thus characterizing the backscatter response efficiently.

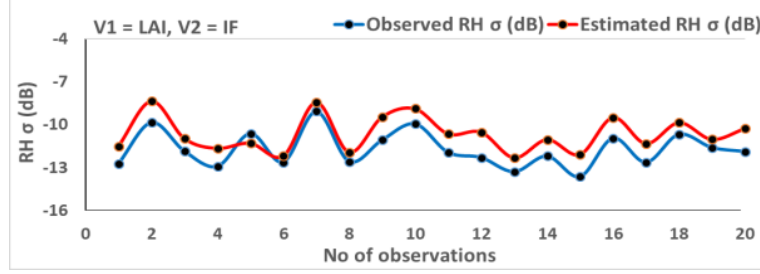

(a)

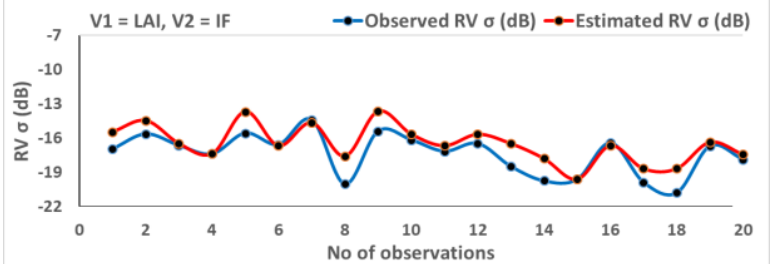

(b)

Figure 6. Observed v/s Estimated (a) RH and (b) RV backscatter for Model IV

\begin{tabular}{|c|c|c|c|}
\hline & Model & $\mathbf{R}^{2}$ & RMSE (dB) \\
\hline \multirow{4}{*}{ RH } & I & 0.55 & 2.21 \\
\cline { 2 - 4 } & II & 0.67 & 2.10 \\
\cline { 2 - 4 } & III & 0.72 & 1.81 \\
\cline { 2 - 4 } & IV & 0.90 & 1.18 \\
\hline & & & \\
\hline \multirow{4}{*}{ RV } & I & 0.40 & 3.53 \\
\cline { 2 - 4 } & II & 0.69 & 2.02 \\
\cline { 2 - 4 } & III & 0.72 & 1.93 \\
\cline { 2 - 4 } & IV & 0.85 & 1.25 \\
\hline
\end{tabular}

Table 4. Model wise $\mathrm{R}^{2}$ and RMSE statistics for RH and RV backscatter

The results of the model were integrated into a GUI. A screenshot of the same has been shown in Figure 7. 


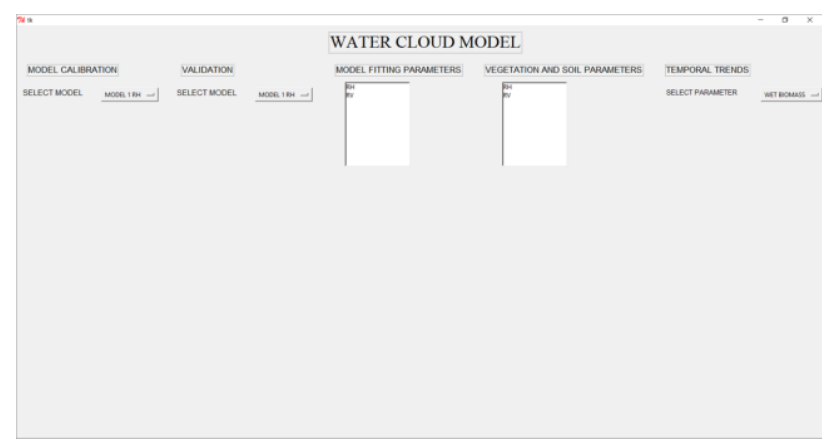

Figure 7. GUI for the WCM

\section{CONCLUSIONS}

The main objective of this study was to improve the parameterization of water cloud model and simulate hybridpolarized backscatter (RH and RV). Several calibration methodologies were tested. The results revealed that WCM calibrated with LAI and IF as the vegetation descriptors along with Levenberg-Marquardt optimized A and B parameters led to significant improvement in the simulation of $\mathrm{RH}$ and $\mathrm{RV}$ backscatter ( $\mathrm{R}^{2}$ of 0.90 and 0.85 respectively) in comparison to other methodologies. These results can be used as an input in several WCM based applications like inverting crop parameters or removing the effect of vegetation (or soil) for the crop (or soil) based studies.

\section{REFERENCES}

Attema, E.P.W., and Ulaby, F.T., 1978. Vegetation modeled as a water cloud. Radio science, 13(2), pp. 357-364.

Ballester-Berman, J.D., López-Sánchez, J.M. and FortunyGuasch, J., 2005. Retrieval of biophysical parameters of agricultural crops using polarimetric SAR interferometry. IEEE Transactions on Geoscience and Remote Sensing, 43(4), pp. 683-694.

Bériaux, E., Waldner, F., Collienne, F., Bogaert, P. and Defourny, P., 2015. Maize Leaf Area Index Retrieval from Synthetic Quad Pol SAR Time Series Using the Water Cloud Model. Remote Sensing, 7(12), pp. 16204-16225.

Bouman, B.A.M., 1991. Crop parameter estimation from ground-based X-band (3-cm wave) radar backscattering data. Remote Sensing of Environment, 37(3), pp. 193-205.

Bouman, B.A.M., Van Kraalingen, D.W.G., Stol, W. and Van Leeuwen, H.J.C., 1999. An agroecological modeling approach to explain ERS SAR radar backscatter of agricultural crops. Remote sensing of environment, 67(2), pp. 137-146.

Cookmartin, G., Saich, P., Quegan, S., Cordey, R., BurgessAllen, P. and Sowter, A., 2000. Modeling microwave interactions with crops and comparison with ERS-2 SAR observations. IEEE Transactions on Geoscience and Remote Sensing, 38(2), pp. 658-670.

Dabrowska-Zielinska, K., Inoue, Y., Kowalik, W. and Gruszczynska, M., 2007. Inferring the effect of plant and soil variables on $\mathrm{C}$-and L-band SAR backscatter over agricultural fields, based on model analysis. Advances in Space Research, 39(1), pp. 139-148.

Doraiswamy, P.C., Hatfield, J.L., Jackson, T.J., Akhmedov, B., Prueger, J. and Stern, A., 2004. Crop condition and yield simulations using Landsat and MODIS. Remote sensing of environment, 92(4), pp. 548-559.

Ferrazzoli, P., Paloscia, S., Pampaloni, P., Schiavon, G., Sigismondi, S. and Solimini, D., 1997. The potential of multifrequency polarimetric SAR in assessing agricultural and arboreous biomass. IEEE Transactions on Geoscience and Remote Sensing, 35(1), pp. 5-17.

Graham, A.J. and Harris, R., 2003. Extracting biophysical parameters from remotely sensed radar data: a review of the water cloud model. Progress in physical geography, 27(2), pp. 217-229.

Green, P.E., 1968. Radar measurements of target scattering properties. Radar astronomy, pp. 1-78.

He, L., Tong, L., Li, Y., Chen, Y., Tan, L. and Guo, C., 2016. Polarimetric analysis of radar backscatter from ground-based scatterometers and wheat biomass monitoring with advanced synthetic aperture radar images. Journal of Applied Remote Sensing, 10(2), pp. 026008-026008.

Inoue, Y., 2003. Synergy of Remote Sensing and Modeling for Estimating Ecophysiological Processes in Plant Production. Plant Production Science, 6(1), pp. 3-16.

Inoue, Y., Sakaiya, E. and Wang, C., 2014. Capability of Cband backscattering coefficients from high-resolution satellite SAR sensors to assess biophysical variables in paddy rice. Remote Sensing of Environment, 140, pp. 257-266.

Le Toan, T., Ribbes, F., Wang, L.F., Floury, N., Ding, K.H., Kong, J.A., Fujita, M. and Kurosu, T., 1997. Rice crop mapping and monitoring using ERS-1 data based on experiment and modeling results. IEEE Transactions on Geoscience and Remote Sensing, 35(1), pp. 41-56.

Macelloni, G., Paloscia, S., Pampaloni, P., Marliani, F. and Gai, M., 2001. The relationship between the backscattering coefficient and the biomass of narrow and broad leaf crops. IEEE Transactions on Geoscience and Remote Sensing, 39(4), pp. 873-884.

Maity, S., Patnaik, C., Chakraborty, M. and Panigrahy, S., 2004. Analysis of temporal backscattering of cotton crops using a semiempirical model. IEEE Transactions on Geoscience and Remote Sensing, 42(3), pp. 577-587.

Mattia, F., Le Toan, T., Picard, G., Posa, F.I., D'Alessio, A., Notarnicola, C., Gatti, A.M., Rinaldi, M., Satalino, G. and Pasquariello, G., 2003. Multitemporal C-band radar measurements on wheat fields. IEEE Transactions on Geoscience and Remote Sensing, 41(7), pp. 1551-1560.

Patel, P. and Srivastava, H.S., 2013. Ground truth planning for synthetic aperture radar (SAR): Addressing various challenges using statistical approach. International Journal of 
Advancement in Remote Sensing, GIS and Geography, 1(2), pp. $1-17$.

Patel, P., Srivastava, H.S. and Navalgund, R.R., 2006. Estimating wheat yield: an approach for estimating number of grains using cross-polarised ENVISAT-1 ASAR data. In Proc. SPIE, Vol. 6410, pp. 641009.

Prevot, L., Champion, I. and Guyot, G., 1993. Estimating surface soil moisture and leaf area index of a wheat canopy using a dual-frequency ( $\mathrm{C}$ and $\mathrm{X}$ bands) scatterometer. Remote Sensing of Environment, 46(3), pp. 331-339.

Raney, R.K., 2007. Hybrid-polarity SAR architecture. IEEE Transactions on Geoscience and Remote Sensing, 45(11), pp. 3397-3404.

Saich, P. and Borgeaud, M., 2000. Interpreting ERS SAR signatures of agricultural crops in Flevoland, 1993-1996. IEEE Transactions on Geoscience and Remote Sensing, 38(2), pp. 651-657.

Said, S., Kothyari, U.C. and Arora, M.K., 2012. Vegetation effects on soil moisture estimation from ERS-2 SAR images. Hydrological Sciences Journal, 57(3), pp. 517-534.

Souyris, J.C., Imbo, P., Fjortoft, R., Mingot, S. and Lee, J.S., 2005. Compact polarimetry based on symmetry properties of geophysical media: The/spl pi//4 mode. IEEE Transactions on Geoscience and Remote Sensing, 43(3), pp. 634-646.

Ulaby, F.T., Allen, C.T., Eger, G. and Kanemasu, E., 1984. Relating the microwave backscattering coefficient to leaf area index. Remote Sensing of Environment, 14(1-3), pp.113-133.

Ulaby, F. T., Moore, R. K., and Fung, A. K., 1986. Microwave remote sensing active and passive-volume III: from theory to applications. 